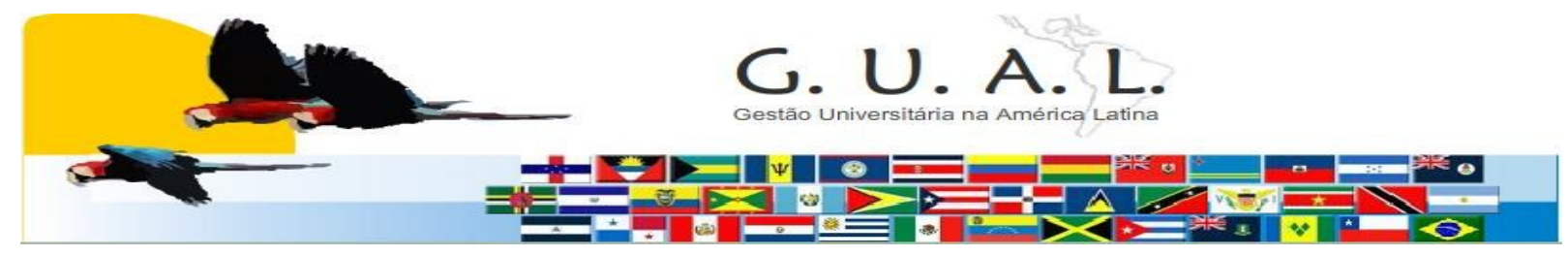

ISSN 1983-4535

\title{
GESTÃO UNIVERSITÁRIA: QUALIDADE, INVESTIGAÇÃO CIENTÍFICA E INOVAÇÃO EDUCACIONAL
}

\section{UNIVERSITY MANAGEMENT: QUALITY, RESEARCH AND EDUCATIONAL INNOVATION}

Maria Estela Dal Pai Franco, Doutora Universidade Federal do Rio Grande do Sul - UFRGS medalpaifranco@ufrgs.br

Mariangela Rosa Afonso, Doutora Universidade Federal de Pelotas - UFPel cafonso@terra.com.br

Luciane Spanhol Bordignon, Mestre Universidade do Oeste de Santa Catarina - UNOESC lu.bordignon@brturbo.com.br

Recebido em 30/outubro/2011

Aprovado em 06/março/2012

Sistema de Avaliação: Double Blind Review

Esta obra está sob uma Licença Creative Commons Atribuição-Uso. 


\title{
RESUMO
}

O estudo objetiva identificar dimensões de qualidade na gestão universitária do conhecimento na perspectiva da pesquisa e da inovação tecnológica, tendo como referência: estudos prévios, políticas governamentais, documentos de evento identificação de convergências temáticas que permitiram a construção de dimensões de qualidade. Evidencia-se que a investigação científica e a inovação educacional de base tecnológica são fatores fundamentais para o desenvolvimento econômico e o bem-estar social a partir de discussão focal, documento da Organização para a Cooperação e o Desenvolvimento Econômico - OCDE de 2010 e Plano Nacional de Educação 2011-2020. As conclusões sinalizam a importância de fontes diversificadas nas dimensões de qualidade, o reconhecimento do potencial de impacto da pesquisa e da inovação tecnológica na qualidade de vida e nas relações sociais, bem com a importância de critérios enraizados nos quadros humanos, na ética e no respeito.

Palavras-chave: Educação superior. Avaliação. Qualidade. Investigação científica. Inovação tecnológica.

\begin{abstract}
The study aims to identify dimensions of quality in university management of knowledge in the perspective of research and technological innovation, with reference to: previous studies, government policy documents identifying convergences themed event that allowed the construction of quality dimensions. It is evident that scientific research and technology-based educational innovation are key factors for economic development and social welfare, with focus discussion from the document of the Organization for Economic Cooperation and Development - OECD, 2010 and the National Education Plan 2011-2020. The findings indicate the importance of different sources in the dimensions of quality, recognizing the potential impact of research and technological innovation in quality of life and social relations, and the importance of criteria rooted in the human frame, ethics and respect.
\end{abstract}

Keywords: Higher education. Evaluation. Quality. Scientific research. Technological innovation. 


\section{INTRODUÇÃO}

É notável o papel da investigação científica e da inovação tecnológica na sociedade do conhecimento. A tendência é que essas questões cresçam junto com os fenômenos da globalização e da internacionalização da Educação Superior (ES) em que pesem críticas de submissão às economias globalizadas e às exigências de uma vigilância crítica. As perspectivas consensuais e convergências sobre esta tendência, além de serem caracterizadas como uma faceta da internacionalização da ES, são acompanhadas por tensões e dúvidas. Por um lado, a investigação científica e a inovação tecnológica podem significar melhoria da qualidade de vida quando são usadas para construir melhores relacionamentos sociais e favorecer a equidade. Por outro lado, a investigação científica e a inovação tecnológica por vezes são apenas submetidas aos critérios econômicos, guiados pelos princípios do mercado e da produção de bens.

Considerando estes aspectos e tendo em conta o caráter de instituições brasileiras de ES, o presente trabalho visa identificar e descrever a qualidade na gestão universitária do conhecimento na perspectiva da pesquisa e da inovação tecnológica, tendo como referência : estudos prévios, políticas governamentais, documentos de evento temático, discussão focal e documento da Organização para a Cooperação e o Desenvolvimento Econômico - OCDE de 2010 .

As seguintes fontes subsidiaram a investigação: estudos anteriores, políticas governamentais, documentos de evento temático, discussão focal e documento da OCDE. O estudo visa a geração de conhecimento e faz parte de uma pesquisa mais ampla, interinstitucional desenvolvida por uma rede de investigadores que tem em mira a qualidade da Educação Superior. ${ }^{1}$

Os seguintes princípios estão presentes no transcurso da análise: a) qualidade tem inúmeros significados e conotações aos quais subjazem lógicas que refletem posturas avaliativas que impregnam as instituições de ES em suas múltiplas facetas, incluindo a gestão; b) a lógica que subjaz ao conceito de qualidade expressa distintos princípios, diretrizes, estratégias de gestão e categorias (SOBRINHO \& RISTOFF, 2005); c) as inovações na educação superior refletem o local - políticas públicas do país, políticas institucionais e

\footnotetext{
${ }^{1}$ A pesquisa interinstitucional visa o desenvolvimento de indicadores de qualidade para brasileiros HE, apoiado pela CAPES (Agência do Governo responsável pela coordenação, melhoramento e desenvolvimento dos Profissionais da Educação), envolvendo quatro grandes universidades públicas e privadas brasileiras articuladas para o desenvolvimento de parcerias para gerar, validar e disseminar o conhecimento por meio de publicação (eletrônica e imprensa) produção científica e técnica.
} 
influências da comunidade, mas também o global. Quanto ao primeiro princípio acima referido, se pode dizer que o conceito de qualidade é multifacetado: existem várias definições, cada uma aplicável à determinados contextos. Ainda enquanto conceito, é um valor conhecido por todos e, no entanto, definido de forma diferenciada por diferentes grupos ou camadas da sociedade, a percepção dos indivíduos é diferente em relação aos mesmos produtos ou serviços, em função de suas necessidades, experiências e expectativas. No que se refere ao segundo princípio entende-se que as lógicas que subjazem aos conceitos de qualidade variam, quanto à sua orientação, num "continuum" entre o humano sob a ótica da emancipação e a visão mercadológica do uso da educação superior e da pesquisa produzida sob o uso primário de bens de consumo. Quanto ao aprofundamento do terceiro princípio, entende-se que o conceito de inovação educacional de base tecnológica é visto sob várias perspectivas. No âmbito global ele é expresso em ideias de documentos de organismos internacionais com força política. No âmbito deste estudo são considerados conceitos da Organização para a Cooperação e o Desenvolvimento Econômico - OCDE de $2010^{2}$ no sentido de identificar e também problematizar a questão da influência global e local na educação superior e na identificação e construção de categorias de qualidade.

\section{ENTRE O LOCAL E O GLOBAL - ESCLARECENDO SENTIDOS}

Antes de adentrar a questão cabe esclarecer que o sentido atribuído ao local, no contexto deste trabalho, abarca as políticas públicas brasileiras, mas também institucionais, além de dados de estatísticas oficiais que refletem a realidade do país.

Um primeiro ponto a destacar, em relação ao local brasileiro é o de que a investigação científica e a inovação tecnológica têm um papel importante nas Universidades. Nesta perspectiva, alguns dados chamam a atenção para a situação brasileira: no ano de 2008, o Brasil, formou 36 mil mestres e 10,7 mil doutores ${ }^{3}$. Os dispêndios nacionais em pesquisa e desenvolvimento (P\&D) selecionados em relação ao produto interno bruto brasileiro (PIB), em 2008, situava-se na porcentagem de 1,09. A distribuição de pesquisadores, em equivalência de tempo integral, em 2008, ficou distribuída: 5,1\% em instituições governamentais, $37,3 \%$ nas empresas e $56,8 \%$ nas instituições de ensino superior. O número

\footnotetext{
${ }^{2}$ Documento Inspirados pela tecnologia, norteados pela pedagogia - OCDE, 2010.

${ }^{3}$ Fonte: GeoCapes/MEC . Disponível em: http://geocapes.capes.gov.br/geocapesds/\#
} 
de pedidos de patentes no Brasil, em 2008, foi de $499^{4}$. Outro dado importante diz respeito a quantidade insuficiente de engenheiros brasileiros. Dos acadêmicos concluintes da graduação $66 \%$ concentram-se na Área da educação e Humanidades e 12,5\%, nas áreas de Engenharia e Ciências Exatas. A Coordenação de Aperfeiçoamento de Pessoal de Nível Superior - CAPES está preparando um programa para impulsionar a formação de engenheiros no país o Plano Nacional Pró-Engenharia cujo objetivo é dobrar em 5 anos o número de engenheiros formados. A principal estratégia é diminuir a evasão dos cursos de engenharia que é em torno de $60 \%^{5}$. Estes dados são pertinentes na reflexão sobre a investigação científica, a inovação tecnológica e Ensino Superior.

No que diz respeito aos aspectos endógenos da Educação Superior - o local- são discutidos neste estudo, dois pontos basilares: a avaliação e a gestão. No caso da avaliação da qualidade da universidade, em especial, os olhares voltam-se basicamente para a investigação de aspectos multidimensionais da ES, na qual se compreende desde os programas estruturais e administrativos da atividade científica, passando pela qualidade dos docentes, discentes e dos equipamentos/infraestrutura, bem como as inovações educacionais de base tecnológica.

Sendo assim, quando se trata da avaliação da qualidade da ES brasileira, na pauta das discussões, estão desde a melhoria da qualidade do ensino; a informação fundamentada da sociedade sobre o desempenho destas instituições; o desenvolvimento de uma cultura institucional interna de garantia de qualidade; a qualificação docente; a relação entre entidades externas à universidade; o compromisso com o estudante; como também a existência de um sistema de avaliação que dê conta das diferentes faces do contexto onde se insere cada instituição.

Nesse sentido, qualquer que seja a procedência avaliativa do elemento "qualidade", na sua essência deve estar a valorização da competência no fazer. Nessa direção Bertolin (2007), ao abordar a questão da qualidade da ES destaca que, o entendimento de qualidade é subjetivo, dependente fundamentalmente das concepções de mundo e de educação superior de quem o emite.

Para Franco (2009) é importante captar olhares meta-teóricos na identificação de categorias sobre avaliação da educação superior. Neste sentido é que traz a contribuição de

\footnotetext{
${ }^{4}$ Fonte: Ministério da Ciência e Tecnologia.. Disponível em: http://www.mct.gov.br/index.php/content/view/5702.html

${ }^{5}$ Fonte: Andifes. Disponível em:

http://www.andifes.org.br/index.php?option=com_content\&view=article\&id=4092:notaveis-criamplano-para-intervir-na-engenharia\&catid $=52 \&$ Itemid $=100013$
} 
diversos olhares meta teóricos derivados de trabalhos sistematizadores de produções científico-acadêmicas sobre Educação Superior, alguns deles apoiados em Bancos de Dados sobre produções acadêmicas diversas, outros específicos de pesquisas e/ou de documentos como artigos e críticas, tendo em comum uma delimitação por meio de critérios inclusivos, sejam geográficos, impressos, temáticos. Mostra que em alguns casos os trabalhos sistematizados se configuram como Estados de Conhecimento por analisarem as informações de produções em bancos de informações e/o obtido as mesmas estruturando-as de acordo com os objetivos e critérios previamente estabelecidos, extraindo delas, construtivamente, categorias.

No caso da gestão da educação superior considera-se que esta envolve decisões estratégicas que refletem os modelos de relacionamento entre as instituições/sistema de ES no nível conceitual (documentos) e/ou práticas do processo decisório e que elas revelam uma racionalidade prevalente. O conceito subjacente de gestão envolve instituições onde a educação tem lugar e seu (s) objetivo(s), compreendem pressuposições sobre a pesquisa/ensino/extensão e princípios de organização (FRANCO, 2007). Gestão exige conhecimento profissional e, principalmente, um núcleo forte e competente de gestão, como condição de sustentabilidade (CLARK, 2003). Desse modo, qualidade - além de um compromisso intrínseco com a nação - torna-se preponderante para a sobrevivência e sucesso das instituições de educação. Podemos dizer que a gestão das instituições de ES deve ser entendida num contexto maior, na esfera das decisões administrativas, governamentais, políticas de planejamento e de avaliação.

Mais do nunca, o princípio da internacionalização tem sido uma das forças integradoras e articuladoras na universidade de um mundo globalizado, transcende críticas aos desdobramentos perversos de gestões econômicas excludentes, não desconsiderando-as mas circunscrevendo-as à crucialidade do conhecimento no desenvolvimento científico e tecnológico para a inserção mais ampla. É o caso de movimentos emblemáticos como o Processo de Bologna ${ }^{6}$, a constituição de grupos de acreditação institucional presentes em diversos continentes e os esforços empreendidos pelas grandes Conferências mundiais da ONU em torno da Educação, em especial da Educação Superior (FRANCO, LONGHI, AFONSO, 2010).

\footnotetext{
${ }^{6}$ O denominado Processo de Bolonha, segundo Neves (2006, p. 15), é o "movimento mais ousado de reforma da educação superior mundo afora." instaurado no final do século passado com vistas à Universidade do Séc. XXI na Europa, de forma
} 
O conhecimento crítico de tais movimentos e dos critérios avaliativos por eles propostos, é decisivo para a universidade que se pretenda inserida num mundo globalizado. A internacionalização da Educação Superior e os critérios isomórficos que implicam, garantia, empregabilidade e comparabilidade, tudo indica, que estão se impondo e pelo menos nas próximas décadas exigirão esforços no sentido de submetê-los aos compromissos sociais (FRANCO, 2009), necessitando para tal, segundo Santos (2007), revigorá-los, ressignificá-los e reinventá-los pela crítica responsável.

$\mathrm{Na}$ perspectiva de que gestão exige conhecimento, este, depende de uma continua criação e recriação de idéias (CARAÇA, FERREIRA E MENDONÇA, 2006). Para estes autores, há três eixos fundamentais: a investigação científica e tecnológica (atividades de investigação em ciência e tecnologia), market research e design (atividades de investigação sobre marketing e desing) e investigação sobre métodos e organizações (atividades de investigação sobre métodos de gestão, formas de organização ou de gestão do conhecimento).

No que diz respeito ao global, e dentro da perspectiva de que organismos internacionais publicam documentos cujas idéias tem força política a organização escolhida para análise é a OECD por meio de alguns de seus documentos com força política que potencialmente influencia a Educação Superior, seus sistemas e instituições.

A Organização para a Cooperação e o Desenvolvimento Econômico- OCDE ${ }^{7}$, é um fórum único, que oferece aos governos ajuda para entender e responder às mudanças e preocupações do mundo atual. Segundo Franco e Morosini, a OCDE nos últimos anos, tem capitaneado discussões sobre educação superior. Em dezembro de 2008, em sua sede de Paris, realizou o seminário: Higher Education to 2030 e buscou responder as seguintes questões: Quais as opções e oportunidades de políticas para responder aos principais desafios do futuro da Educação Superior em termos de acesso, capacidade e aquisição? Como a expansão da educação superior influencia a redução das iniqüidades sociais? Como podem ser financiados os desafios da educação superior? Como a globalização influencia o papel e a governança do futuro da educação superior? Para responder a estas perguntas foram pensados quatro possíveis cenários e suas imbricações. O primeiro cenário para a educação superior seria o do predomínio de redes colaborativas; o segundo, a educação superior teria como predomínio os interesses da comunidade; um terceiro cenário teria como predomínio a educação superior

\footnotetext{
${ }^{7}$ Os países membros da OCDE são: Alemanha, Austrália, Áustria, Bélgica, Canadá, Chile, Coréia, Dinamarca, Eslovênia, Espanha, Estados Unidos, Finlândia, França, Grécia, Hungria, Holanda, Islândia,Itália, Japão, Luxemburgo, México, Noruega, Nova Zelândia, Países Baixos, Polônia, Portugal, Reino Unido, República Tcheca, República Eslovaca, Suécia, suíça e Turquia.
} 
com novas responsabilidades públicas; e o último cenário a educação superior teria o predomínio do caráter comercial.

Em 2010, a OCDE lançou um documento: Inovação Educacional de Base Tecnológica, direcionado para a questão de como as inovações educacionais de base tecnológica pode ser monitorada, avaliada e expandida em larga escala. Esta publicação é o resultado de uma cooperação com o Estado de Santa Catarina - Brasil, partindo de uma conferência internacional realizada em Florianópolis, capital do Estado, em 2009.

O termo Inovação Educacional de Base Tecnológica ${ }^{8}$, de forma semelhante ao conceito de qualidade, também se configura como polissêmico. A estratégia adotada pela OCDE foi a de procurar responder as questões que envolvem a inovação tecnológica, por meio do Centro de Pesquisa e Inovação Educacional (Centre for Educacional Research and Innovation) - CERI. Este centro tem discutido como os sistemas gerenciam a educação a partir de duas perspectivas distintas: a perspectiva do capital humano e a perspectiva sistêmica.

Segundo a OCDE, na perspectiva do capital humano, o CERI analisa como este capital está contribuindo para a inovação assim como a inovação em educação pode ser promovida. A perspectiva sistêmica, segundo o organismo, tem sido aplicada com sucesso em duas diferentes áreas; na educação e treinamento vocacional e nos recursos de aprendizagem. Já a inovação educacional é definida como qualquer mudança dinâmica que tenha como objetivo agregar valor aos processos educacionais que promovam resultados mensuráveis, seja em termos de satisfação dos parceiros, ou em termos de desempenho educacional (CERI, p.12, 2010).

Os resultados indicados mostram que os países têm apoiado, no plano político, as inovações baseadas em tecnologias, e esforços tem sido importantes em três dimensões: determinar as condições que permitem a adoção de tecnologia, instrumentalizar e apoiar os professores para gerarem inovações e fornecer apoio para a comunidade de pesquisa interessada em documentar e analisar inovações educacionais emergentes.

Três questões permeiam a inovação educacional com base em tecnologia, segundo a OCDE: conceitos de inovação educacional de base tecnológica que competem: como inovação educacional com base em tecnologia é definida e compreendida? Porque as inovações educacionais de base tecnológica devem ser fomentadas? As dinâmicas da inovação educacional de base tecnológica na perspectiva da gestão do conhecimento:

\footnotetext{
${ }^{8}$ Dados obtidos do documento da OCDE 2010.
} 
quais são os principais modelos de inovação nos países da OCDE? Quais são os fatores sistêmicos envolvidos? Políticas de inovação que dizem respeito à tecnologia em educação: como as políticas de inovação são desenhadas? Qual é o papel da evidência em pesquisa em nutrir as políticas de inovação? Como estas políticas são monitoradas e avaliadas?

Neste contexto, a pesquisa produzida na Universidade tem papel fundamental. A pesquisa é definida pela OCDE como o processo de criação de conhecimento que, de acordo com os padrões cultos, pretendeu autorizar sua validade e fidelidade. A inovação, segundo a OCDE, depende pesadamente da criação de conhecimento básico, através da educação e ciência. Um sistema de educação de boa atuação facilita a adoção e difusão de inovação, por fornecer capital humano para inovação e pela inovação dentro da educação e treinamento. Um sistema de educação de boa atuação também significa um sistema em harmonia com as mudanças que estão acontecendo na sociedade, tais como a globalização, desenvolvimento tecnológico e o crescimento de uma quantidade de aprendizagem informal que está acontecendo fora do sistema de educação.

As lições aprendidas e implicações políticas fazem parte das conclusões preliminares e resumem as lições tiradas do encontro de especialistas da OECD em Florianópolis- Brasil, em novembro de 2009:

a) há uma falta de equilíbrio entre os investimentos em infraestrutura, conteúdo, apoio e treinamento de professores e os esforços necessários para a construção de uma base de conhecimentos sustentável em relação às inovações educacionais baseadas em tecnologia;

b) há uma tensão entre a tecnologia e a pedagogia;

c) há um eixo entre a inovação radical e a incremental;

d) há uma necessidade de se equilibrar as expectativas do poder da tecnologia com a realidade do que é possível;

e) a complexidade das questões em pauta exigem uma abordagem multicamada, multidisciplinar e multimetodológica;

f) o potencial de "novas" disciplinas de pesquisa tais como a pesquisa de cérebro e a pesquisa de ambientes de aprendizagem precisam ser exploradas;

g) o trabalho atual sobre a avaliação parece ser limitado ao conhecimento digital;

h) há uma necessidade de um diálogo social sobre as inovações educacionais envolvendo os parceiros;

i) a pesquisa pode ser traduzida em direcionamentos significativos para melhoria da prática.

A OCDE deixa uma questão aberta, passível de debates: até onde o resultado da pesquisa está sendo introduzido na educação e na prática dos professores? Esta questão aberta 
levanta duas discussões importantes: primeiro os sistemas educacionais precisam assegurar a disponibilidade do resultado da pesquisa relacionada a tecnologia e ao aprendizado ser disponibilizado num formato acessível ao professor. Segundo, a cultura e o desenvolvimento profissional dos professores deveriam dar atenção também ao resultado da pesquisa como parte do ethos profissional entre os professores. Um terceiro item está relacionado à questão das instituições que formam professores, se realmente conseguem estar a frente do desenvolvimento do discurso em tecnologia em ensino e aprendizagem.

Complementa as conclusões complementares da OCDE, Caraça, Ferreira e Mendonça (2006), ao aferirem que o processo de inovação gera resultados em termos de: inovação de produto (bens ou serviços novos ou melhorados), inovação de processo (novos ou melhorados processos de produção, métodos de distribuição ou atividades de apoio aos bens ou serviços), inovação de marketing (alterações fundamentais nos métodos de venda e de marketing, no design do produto ou nas suas embalagens) e inovação organizacional (alterações fundamentais na estrutura da empresa e na organização do trabalho, nos sistemas de gestão do conhecimento ou nas relações com o exterior).

Sebarroja (2001) argumenta que a inovação aprofunda aspectos importantes de uma nova formação compreensiva e integral destacando componentes e objetivos do processo de inovação educativa, entre eles: aquisição do conhecimento, mas também a compreensão daquilo que dá sentido ao conhecimento e geração de um foco de agitação intelectual permanente. $\mathrm{O}$ autor realça alguns fatores basilares para promoção da inovação. Entre os fatores apontados destaca-se: equipes docentes sólidas e comunidade educativa receptiva, redes de intercâmbio e cooperação, assessores e colaboradores críticos e outros apoios externos, institucionalização da inovação e vivência, reflexão e avaliação.

Prusak (2007) aborda formas de trabalhar o conhecimento como unidade de análise para o desenvolvimento da inovação: diversidade cognitiva (o surgimento do novo conhecimento é utilizado de forma nova, combinada, discutida e trabalhada por pessoas que possuem diferentes inclinações, normalmente, por meio da educação, do treinamento e da experiência intelectual e vocacional), ampliar a conversação ( com a informação de muitos é mais provável ter um resultado melhor do que com a opinião de poucos), pontes e junções ( o conhecimento é disseminado pelas pessoa, algumas vezes intencionalmente, outras por acaso. Estas pessoas reúnem fontes inestimáveis para a inovação. O Banco Mundial os chama de pontes ou junções, uma vez que são pessoas-chave no desenvolvimento de redes), espaço (profissionais especializados em desenvolver espaços que favorecem a criação de 
conhecimento), concentração nas práticas (por meio delas que se pode conseguir uma abordagem mais intensa da inovação pautada no conhecimento).

Neste contexto de reflexão, em uma perspectiva projetista, o Plano Nacional de Educação 2011-2020, apresenta várias metas, que segundo o ministro da Educação Jorge Adadi, o novo plano terá como foco a valorização do magistério e a qualidade da educação.

Dentre as metas descritas no Plano, para este estudo, serão analisadas a de número 12 e 14 que referem-se ao Ensino Superior. A meta número 12 salienta a elevação de forma qualificada a taxa bruta de matrícula na educação superior para 50\% e a taxa líquida para 33\% da população de 18 a 24 anos. A nota técnica desta meta salienta que no âmbito macro, também é inquestionável a relevância da educação, e principalmente a educação superior, para a caminhada rumo ao desenvolvimento e da geração de inovações tecnológicas e dinamismo econômico. Já a meta número 14 reporta para elevação gradual do número de matrículas na pós-graduação strictu sensu de modo a atingir a titulação anual de 60 mil mestres e 25 mil doutores.

A nota técnica ressalta que o sistema de $\mathrm{C} \& \mathrm{~T}$ do Brasil conta com uma infraestrutura e um modelo de capacitação de recursos humanos de alto nível que tem propiciado inúmeros benefícios concretos, possibilitando ao Brasil expandir sua autonomia científica e tecnológica em curto prazo. Salienta que além do investimento dos setores públicos na pós-graduação, o setor empresarial também deve ser estimulado a ampliar os seus recursos a serem aplicados em treinamento e capacitação de mestres e doutores. Decorre disto importância de políticas específicas implementadas a fim de estimular a cooperação e integração de todos os segmentos da sociedade em busca de maior capacidade de inovação e , consequentemente, de competitividade para evitar que o setor acadêmico continue distante do setor de inovação tecnológica.

Reitera-se o papel relevante da Educação Superior no que diz respeito à gestão universitária na perspectiva da pesquisa, da investigação científica e da inovação educacional.

\section{INDICADORES METODOLÓGICOS: FONTES PARA IDENTIFICAÇÃO DAS DIMENSÕES DE GESTÃO DA QUALIDADE}

Foram distintas as fontes que corroboraram para a identificação de dimensões de qualidade na gestão institucional da pesquisa, na ES tendo em vista a avaliação da qualidade da gestão institucional de pesquisa. Tais fontes podem ser entendidas como formas de gerar conhecimento. São elas: resultados de estudos anteriores; indicações de políticas públicas para 
o ES e Ciência e Tecnologia; indicações de documentos apresentados em uma sessão especial de um evento específico sobre o tema; discussão focal por especialistas a partir de resultados da análise de conteúdo dos documentos e de documento da OCDE.

\subsection{Resultados de Estudos Anteriores}

A construção das categorias de qualidade tomou como base os estudos e pesquisas anteriores realizados (Morosini \& Franco, 2009; Tight, 2003; Kuh, 2008) sobre o RIES 9 Rede Sul Brasileira de Pesquisadores em Educação Superior, o Grupo de Estudo sobre Universidade - GEU na Universidade Federal do Rio Grande do Sul (UFRGS). Tensões relacionadas com a qualidade na gestão universitária e administração em nível institucional e do sistema foram identificadas por Franco (2009). A autora analisou estudos internacionais, já apresentados em congressos (EAIR, 2008), bem como os estudos brasileiros (RIES, 2009). Os resultados mostraram que as tensões ligadas à criação do sistema internacional, a expansão ES através da mobilidade acadêmica, a globalização e a identidade local são as principais tendências. Ao nível institucional, as tensões estão ligadas à gestão democrática, e administrativas e inovação institucional. Eles são permeados por questões público-privadas.

\subsection{Políticas Brasileiras de Avaliação da Educação Superior e da Ciência e Tecnologia}

Para construção de categorias para avaliar a qualidade na gestão institucional da pesquisa foram considerados os documentos e estratégias governamentais ligadas à avaliação da Educação Superior e da Ciência e Tecnologia.

INEP e SINAES - os documentos e as estratégias do INEP - Instituto Nacional de Pesquisa - são fontes importantes para identificar as categorias de qualidade. As principais responsabilidades do INEP são a organização e manutenção do sistema de educação e informação estatística, o planejamento e direções de desenvolvimento de sistemas e projetos de avaliação educacional que visam estabelecer indicadores de desempenho da educação no país. Ele coordena o processo de avaliação dos cursos de graduação, em conformidade com a legislação vigente, definindo parâmetros e propondo critérios e mecanismos de ES, bem como

\footnotetext{
${ }^{9}$ RIES- fundada em 1999. Em 2006, foi escolhido como um Centro de Excelência em Ciência e Tecnologia do Estado do Rio Grande do Sul em Educação (Núcleo de Excelência em Ciência e Tecnologia Estado do Rio Grande do Sul na área de Educação) pelo CNPq-Conselho Nacional de Pesquisa e FAPERGS-Fundação de Pesquisa do Estado-RS. Em 2007, foi escolhida como a CAPES / INEP Observatório da Educação para desenvolver estudos sobre indicadores de qualidade no ensino superior.
} 
a ações conjuntas de apoio institucional, técnico e financeiro, cooperação bilateral e multilateral nacionais, estrangeiras e internacionais.

O Sistema Nacional de Avaliação da Educação Superior (SINAES) é composto por avaliação institucional (interna e externa de avaliação a cada três anos), avaliação de cursos de graduação (in loco por comissões) e Comissão de Avaliação. Para gerar os seus dados e estudos educacionais o Inep coleta dados estatísticos e executa a análise avaliativa em todos os níveis e modalidades de ensino. Em relação à avaliação da produção do conhecimento e da investigação, a base de avaliação do SINAES usa os seguintes indicadores:

a) a coerência entre os compromissos fundamentais da instituição;

b) a forma de grupos de pesquisa estão organizadas em IES, as necessidades dos laboratórios, bibliotecas e outras estruturas de base para a promoção da investigação;

c) as políticas de formação de professores e investigadores, bem como o interesse em intercâmbio e cooperação entre as instituições;

d) a relação com a indústria e outros segmentos da sociedade;

e) as relações com as organizações regionais e internacionais, associações científicas.

Lei de Inovação Tecnológica ${ }^{10}$ - No contexto das diferentes políticas públicas e estratégias que facilitam a produção e avaliação da pesquisa em ES, a Lei de Inovação Tecnológica é um marco. Ela regula o relacionamento entre as universidades e as empresas, incentivando o investimento em inovação e produção científica, aliando também a atividade industrial. Esta lei é essencial para a ES na medida em que fornece uma oportunidade para a criação de centros de inovação e tecnologia, responsáveis pelo desenvolvimento e surgimento de empresas, desenvolvimento de produto e de pedido de patente, potencializando a geração de processos de mudança na comunidade acadêmica e, em especial, no mercado. A Lei de Inovação, também garante subsídios para o processo de desenvolvimento e estabelecimento de parcerias entre universidades e empresas possibilitando avanços na produção, inovação tecnológica e aceleração das patentes.

CNPq - Conselho Nacional de Pesquisa - duas ações governamentais importantes para a identificação das categorias de qualidade emergem do Conselho Nacional de Pesquisas: a plataforma Lattes e o Diretório dos Grupos de Pesquisa brasileiros. A Plataforma Lattes é um banco de dados, com acesso gratuito que fornece conhecimentos sobre o processo de

${ }^{10}$ A Lei de Inovação Tecnológica - Lei n. 10,973 2 de dezembro de 2004 as regras sobre os incentivos à inovação e à pesquisa científica e tecnológica no ambiente produtivo, que prevê outras medidas, critérios, incentivo, inovação, investigação científica e tecnológica, cooperação, partnerhsip, universidade, instituição científica, empresas privadas, o desenvolvimento científico , desenvolvimento tecnológico, o desenvolvimento industrial. 
formação e desenvolvimento da carreira dos professores. O acesso ao curriculum vitae de docentes, pesquisadores e estudantes fornece indicadores de produção científica e tecnológica e contribui para implementação de políticas de gestão no Ensino Superior.

A avaliação dos programas de pós-graduação está centrada em áreas e linhas de pesquisa, estrutura curricular, funcionamento e condições infraestruturais, docentes, estudantes e produção acadêmica. A produção de conhecimento tem sido o critério de avaliação decisivo para a Pós-Graduação. A articulação entre o banco de dados e outras fontes de plataforma permite o acesso a um vasto conjunto de informações científicas.

O CNPq tem realizado acordos institucionais visando ampliar a visibilidade, utilidade e confiabilidade das informações constantes na Plataforma Lattes, e as instituições parceiras têm se beneficiado ao ampliar os recursos oferecidos aos seus usuários. A integração da Plataforma Lattes com bases de dados de outras instituições, tem garantido o acesso, a partir do currículo do pesquisador, a um vasto acervo de informações científicas. A Plataforma Lattes é uma base de dados pública, tanto no que se refere ao ingresso quanto à recuperação das informações através da Internet.

Apesar da disponibilização pública das informações, instituições de ensino, pesquisa e inovação do País têm solicitado ao CNPq o acesso aos dados curriculares de seus professores, pesquisadores, alunos e colaboradores, com o objetivo integrar os dados do Lattes aos seus sistemas de informação, gerar indicadores internos de produção científica e tecnológica, realizar estudos através da aplicação de ferramentas de mineração de dados, e apoiar a implementação de políticas de gestão.

Também no que diz respeito aos mecanismos institucionais para organizar a produção de pesquisa das universidades, o Diretório dos Grupos de Pesquisa no Brasil (DGPB), CNPq, desempenha um papel crucial em fornecer informações sobre a atividade de pesquisa no país. O DGPB mantém uma base em curso, com informações atualizadas continuamente pelos líderes do grupo, pesquisadores, estudantes.

As informações contidas neste banco de dados relacionam grupos constituídos por recursos humanos (pesquisadores, estudantes e técnicos), linhas de pesquisa e conhecimento especializado, os setores envolvidos, científica, tecnológica e artística padrões de interação com o setor produtivo. Ele permite descrever os limites e o perfil da pesquisa científicotecnológica no Brasil e tem sido utilizado pela comunidade científica e tecnológica em geral e pelos comitês consultivos CNPq, em particular, como uma ferramenta para orientar as suas 
atividades. Os grupos de pesquisa estão localizados em universidades, instituições isoladas de ensino superior, institutos de pesquisa científica, institutos tecnológicos.

\subsection{Documentos de um evento sobre qualidade da Educação Superior}

Os documentos selecionados para análise fizeram parte do programa do evento "Vozes da Comunidade", na qual vários especialistas de diferentes áreas e tipos de instituições de ES apresentaram estudos e pesquisas que pontuaram elementos importantes sobre a qualidade da Educação Superior. O evento foi promovido por três grupos distintos: o RIES - Rede Sul Brasileira de Pesquisadores em Educação Superior, o Grupo de Estudo sobre Universidade GEU na Universidade Federal do Rio Grande do Sul (UFRGS), e o Grupo InovAval - Grupo de Pesquisa em Inovação e Avaliação (UFRGS). O objetivo do RIES é configurar a educação superior como um campo de produção de investigação em instituições de Ensino Superior. Ele também visa esclarecer a produção acadêmica na área de conhecimento e desenvolvimento de condições para a produção, para consolidar as redes de investigadores e identificar os indicadores de qualidade para avaliar o Ensino Superior ${ }^{11}$.

Focalizamos neste estudo a sessão sobre a qualidade na gestão institucional a partir dos documentos (artigos e comentários analíticos) originais dos pronunciamentos feitos. A metodologia aplicada para identificar as categorias de qualidade na gestão institucional da pesquisa foi a análise de conteúdo (GRAWITZ, M., 1967) resgatando os pontos centrais e convergências temáticas para identificar as categorias.

\subsection{Grupo Focal: estudos sobre os resultados da análise de conteúdo}

A técnica de obtenção de dados a partir dos grupos focais pode ser caracterizada como um recurso para compreender o processo de construção das percepções, atitudes e representações sociais de grupos. Esta técnica pode ser utilizada para a exploração de um tema pouco conhecido, visando o delineamento de pesquisas futuras. (GONDIM, 2002). A utilização dos grupos focais está relacionado com os pressupostos e premissas do pesquisador.

${ }^{11}$ CNPq - Conselho Nacional de Desenvolvimento Científica e Tecnológico e da CAPES / MEC Coordenação de Aperfeiçoamento e Capacitação de Pessoal de Nível Superior são as agências de desenvolvimento principal para a Ciência, Tecnologia e Inovação no Brasil, e FAPERGS - Fundação de Amparo a Pesquisa do Estado do Rio Grande do Sul realiza o desenvolvimento em nível estadual. INEP / MEC - Instituto Nacional de Estudos e Pesquisas Educacionais Anísio Teixeira do Ministério da Educação promove a produção analítica sobre a educação no Brasil. 
Assim o estudo foi construído a partir das discussões em reuniões consecutivas com especialistas que buscavam identificar e categorizar os resultados encontrados na análise de conteúdo dos documentos produzidos pelo evento "Vozes da Comunidade" sobre a qualidade da gestão institucional de pesquisa. O grupo foi composto por cinco especialistas de diferentes instituições de ES sugeriu ajustes conceituais e redirecionamento de alguns aspectos teóricos e metodológicos, procurando um refinamento das categorias construídas previamente.

As discussões também foram estimuladas por temas, tendo com base em documentos nacionais e internacionais, que indicaram a adequação de uma abordagem de desenvolvimento que procuram novas categorias. Ressaltamos que o grupo focal agiu como uma revisão por pares críticos e estava no cerne da geração de conhecimento e processo de validação. Nesse contexto, houve a preocupação em sinalizar os possíveis indicadores para avaliar a qualidade do ES tomando como referência o desempenho os discursos dos sujeitos participantes dos grupos focais.

\section{PANORAMA DAS DIMENSÕES DE QUALIDADE NA GESTÃO DA PESQUISA NA EDUCAÇÃO SUPERIOR}

As dimensões identificadas resultam de convergências temáticas de declarações, assertivas e indicadores presentes nas varias fontes, constituindo-se uma produção do conhecimento:

- Políticas institucionais e sistema de decisão sobre pesquisa: o conhecimento como missão da universidade; espaço organizacional e estrutural para a tomada e implementação de decisões, incluindo as unidades centrais e do governo e da administração com a participação do corpo acadêmico, bem como de profissionais altamente especializados (conselhos, unidades, departamentos). "Núcleo central fortalecido" (CLARK, 2003); participação das partes interessadas, comitês decisórios sobre ética em pesquisa e transferência tecnológica;

- Responsabilidade Social da Instituição de Educação Superior: cultura de ética em pesquisa, respeitando os direitos de autoria; mecanismo de transferência de tecnologia, políticas e atividades institucionais de conhecer o contexto do programa de investigação internacional, nacional e local; programas de pesquisa institucional voltados para a comunidade e problemas sociais, programas inovadores de investigação para revitalizar a instituição de Ensino Superior em suas relações sociais.

- Políticas e programas para fomento da pesquisa - Previsão e busca de fontes de financiamento; programas institucionais para promover a investigação, incluindo as políticas e estratégias para lidar com as restrições financeiras, atividades empresariais e programas de captação de recursos; programa de iniciação científica para alunos de graduação, fontes de financiamento diversificadas; 
- Gestão da informação e socialização do conhecimento: os meios de divulgação de informação (sites, revistas, pastas, bases de dados) sobre as políticas e programas institucionais, divulgação de documentos nacionais e internacionais pertinentes, fontes de programas de ciência e tecnológica com financiamento público e privado; bases de dados de pesquisa aprovado no plano institucional, pesquisas com financiamento, bolsas de iniciação científica, bolsas de pós-graduação, bolsas de pós-doutorado, prêmios de produtividade, s pesquisadores financiados, produção e mobilidade acadêmica.

- Qualificação acadêmica profissional/ funcional e sustentabilidade: número de doutores, professores trabalhando em tempo integral, professores com tempo disponível para a pesquisa, número de grupos de pesquisa, distribuição de grupos de pesquisa em diferentes áreas do conhecimento, flexibilidade para participar de pesquisas interdepartamentais e interdisciplinares; políticas para qualificar professores e outros profissionais de Educação Superior; políticas de carreira para professores e profissionais, produção acadêmica;

- Impacto acadêmico, social e econômico da pesquisa e transferência de tecnologia: o uso de novas tecnologias; construção de mecanismos de transferência de tecnologia; resultados para a sociedade, mecanismos de avaliação do impacto de pesquisa na comunidade, empresas, estudos para auferir impacto/resultados; cooperação e parcerias com diferentes setores da sociedade.

\section{CONCLUSÕES}

O desenvolvimento do estudo permite reafirmar que o conceito de qualidade é multifacetado, sendo muitas as definições aplicáveis a determinados contextos. Tem subjacentes variações de princípios e valores que transitam num "continuum" entre o humano, sob a ótica da emancipação e uma visão mercadológica, sob a ótica do uso da educação superior e da pesquisa que enfatiza o uso primário de bens de consumo. O conceito de inovação educacional de base tecnológica é visto sob várias perspectivas.

A perspectiva da OECD não pode ser omitida pela força que o organismo exerce sobre a educação superior, com desdobramentos em políticas da educação superior brasileira. Problematizar, especialmente quando se une qualidade na gestão e inovação, é procedente e necessário, pois o local não pode ser diluído no global, tendo presente a identificação e a construção de categorias de qualidade.

O conceito de inovação necessita ser estendido além do mercado, indo ao encontro do atendimento das necessidades e demandas da população. A inovação está atrelada a investimentos (financeiros, humanos) e envolve a utilização de um novo conhecimento ou de novos usos para conhecimentos já existentes. A base para a inovação é o conhecimento e este 
se assegura na formação educacional. A Ciência gera o conhecimento, a tecnologia se configura como aplicação deste conhecimento e a inovação deve atender as necessidades sociais. Neste sentido se configura a importância da pesquisa nas Universidades.

Um dos principais desafios é a construção de políticas tecnológicas inovadoras pelas Universidades, por meio de redes de pesquisa, projetos interdisciplinares, na dimensão emancipatória, ambiental e sustentável. A cooperação local, nacional e internacional é uma forma eficiente de compartilhar conhecimento.

Neste sentido, quanto às políticas e programas de fomento à pesquisa segundo Franco, Longhi e Afonso (2010), torna-se indispensável a existência de programas institucionais de fomento à pesquisa, onde existam programas de sustentabilidade financeira e de manutenção para permanência de grupos e de linhas de pesquisa com mecanismo de controle dos recursos para orçamento institucional para fomento; a busca e captação de recursos de programas de agências de fomento (público e privado), bem como mecanismos de controle dos recursos gerados pelas agências de fomentos para pesquisadores.

A qualidade da investigação científica parece ser influenciada pelas relações decisivas, mantidas entre práticas científicas e práticas no contexto institucional, como a transferência de conhecimento, cultura de inovação e as condições e mecanismos de instituições sociais, incluindo os governos locais e internacionais e agências multilaterais.

As seguintes fontes foram utilizadas para a busca de convergências temáticas caracterizadoras das dimensões: resultados de estudos anteriores, indicações de políticas públicas no Ensino Superior e da Ciência e Tecnologia; análise de conteúdo dos documentos apresentados por especialistas em uma sessão temática de um evento e estudo focal com discussão por peritos sobre os resultados da análise de conteúdo dos documentos. As dimensões identificadas estão relacionadas com a produção do conhecimento em relação às quais indicadores podem ser desenvolvidos: políticas institucionais e sistema de decisão sobre pesquisa; responsabilidade social da Instituição de Educação Superior; políticas e programas para fomento da pesquisa; gestão da informação e socialização do conhecimento; qualificação acadêmica profissional/funcional e sustentabilidade; Impacto acadêmico, social e econômico da pesquisa e transferência de tecnologia.

Embora as declarações e os descritores caracterizem cada dimensão de qualidade, eles simplesmente sugerem caminhos por meio dos quais e nos quais indicadores de qualidade poderiam ser desenvolvidas e teórica e metodologicamente refinadas. Grupos focais, por exemplo, são considerados como meios para socializar e impregnar o processo de 
interlocução com a crítica, dando uma dimensão social ao processo de geração de conhecimento. Na verdade, a produção do conhecimento e da investigação científica foram considerados como produção incessante, que reúne as condições sociais, além de teóricas e metodológicas. Como tal, não é surpresa que as categorias são consideradas suscetíveis à mudança.

Para que isso aconteça são necessárias várias estratégias: a promoção de articulação entre conhecimento localizado e contextualizado por parte das instituições; o estabelecimento de condições políticas/estratégicas para desenvolvimento de cultura de pesquisa; a criação de espaços propícios para a geração de conhecimentos inovadores e vinculação da produção do conhecimento com os espaços criados; a promoção de relações entre grupos de pesquisa, inclusive de distintos campos de conhecimento bem como o incentivo às tecnologias e projetos inovadores. (FRANCO, LONGHI, AFONSO, 2010)

É reconhecido que a investigação científica é a melhoria da qualidade de vida e em alguns casos, tem sido usada para construir melhores relações sociais. No entanto, todas as fontes de dimensões de qualidade, apontaram para a importância de que critérios de qualidade na gestão assentem-se na ética, justiça e respeito pelas pessoas.

\section{REFERENCIAS}

ANDIFES. Disponível em:

http://www.andifes.org.br/index.php?option=com_content\&view=article\&id=4092:notaveiscriam-plano-para-intervir-na-engenharia\&catid $=52 \&$ Itemid $=100013$. Acesso em: $02 \mathrm{dez}$ 2010.

BRASIL. Ministério da Ciência e Tecnologia. Disponível em: http://www.mct.gov.br/index.php/content/view/5702.html. Acesso em: 02 dez 2010.

CARAÇA, João; FERREIRA, João; Mendonça, Sandro. Desenvolvimento sustentado da inovação empresarial: modelos de inovação. Disponível em: http://gestaodeinovacao .com/imagens/stories/ERI AUGUSTO/modelo cadeia.pdf. Acesso em: 02 out. 2011.

CLARK, Burton. R. "Sustaining changes in universities: continuities in case studies".Tertiary Education \& Management (TEAM).Netherlands, Kluwer Academic Publishers, Vol 9 No.2, 2003 p.99-116.

CNPq Diretório dos Grupos de Pesquisa no Brasil disponível in: http://dgp.cnpq.br/diretorioc/html/ infogeral/ e http://dgp.cnpq.br/censo2004 /inf_gerais/aquisicaodados.htm .Jan.15, 2010

FRANCO . M E D. P. “Qualidade na Gestão Universitária.In: Rethinking Inequalities”. XXVIII International Congress LASA 2009. R Janeiro, Brasil, 11 - 14 June 2009. 12 
FRANCO, M.E.D.P. "Política e Gestão da Educação Superior: Discutindo a construção de categorias e repercussões na formação do professor". Porto Alegre V Congresso LusoBrasileiro Política e Administração da Educação. Porto Alegre,UFRGS/ ANPAE/ FPSE/E.F.E.E,2007,12p.(CDROM).

FRANCO, M.E.P.; LONGHI, S. AFONSO, M. R. Indicativos de qualidade na Gestão da Universidade: Dimensões e critérios em questão. Porto Alegre. Texto para Workshop FACED UFRGS/2010, (CDROM).

EAIR-The European Higher Education Society. "30th ANNUAL EAIR FORUM" 24 to 27 Aug. 2008, Copenhagen, Denmark ( $<$ http://www.eair.nl/ Newhome/template/ forum/ $>$. Acessado Oct. 2008).

INEP http://www.inep.gov.br/institucional/ e http://www.telecentros. desenvolvimento. gov.br/sitio/destaque.php?sq_conteudo=3772 em 15/01/2010.

HARVEY, Lee. "New Realities: the relationship between higher education and employement”. European Association of Institutional Research. Lund: august, 1999.

GEOCAPES/MEC . Disponível em: http://geocapes.capes.gov.br/geocapesds/\#. Acesso em: 02 dez. 2010.

GONDIM, Sônia M.G.. "Grupos focais como técnica de investigação qualitativa: desafios metodológicos". Paidéia (Ribeirão Preto) [online]. 2002, vol.12, n.24 [citado 2010-0116],pp.149-161.Disponível: $<$ http://www. cielo.br/scielo.php?script=sciarttext\&pid=S0103863X2002000300004>ISSN0103-86X.

GRAWITZ, Madeleine. "Le Techniques au service des sciences sociales" (Livro III). In: PINTO, Roger \& GRAWITZ, Madeleine. Méthodes des Scienses Sociales. Paris: Livrairie Dalloz, 1967.

KUH, George D. "High Impact Educational Practice". Washington DC, AAC\&U,2008.

MOROSINI, M.C.; FRANCO, M.E.D.P. "Produção Científica sobre Educação Superior: cooperação na Comunicação e Disseminação do Conhecimento. "ProceedingsThe 3nd International Conference on Knowledge Generation, Communication and Management/ (The 13th WMSCI. V.VII. Florida, IIIS, 2009 p.157

MOROSINI, M.C.; FRANCO, M.E.D.P. "Building categories in Higher Education Pedagogy: from the Generation to the Socialization of Knowledge”. Proceedings KGCM The 2nd International Conference on Knowledge Generation, Communication and Management/The 12th WMSCI-V.VII. Florida, IIIS, 2008, p. 294-298 ISBN-10:193427237X .

OCDE. "Inspirados pela tecnologia, norteados pela pedagogia". 2010.

PRUSAK, Larry. Conhecimento e inovação. In: TERRA, José Claudio Cyrineu (org). Inovação: quebrando paradigmas para vencer. São Paulo: Saraiva, 2007. 
SEBARROJA, Jaume Carbonell. A aventura de inovar: a mudança na escola. Porto; Porto Editora, 2001.

SOBRINHO, J. D; RISTOFF, D. "Dilemas da educação superior no mundo globalizado. Sociedade do conhecimento ou economia do conhecimento?". São Paulo: Casa do Psicólogo,2005. 13

TIGHT,Malcolm."Researching Higher Education. " London/ Berkshire, England: SRHE (Society for Research into Higher Education), Open University Press, McGraw-Hill Education, 2003. 257 p.

UNIVERSITAS. Disponível em: http://www.pucrs.br/faced/ pos/ universitas, 2009. Acesso em 29/09/2011.

SINAES - "Sistema Nacional de Avaliação da Educação Superior: da concepção à regulamentação" 2. Ed., ampl. - Brasília: Instituto Nacional de Estudos e Pesquisas Educacionais Anísio Teixeira, 2004. 155 p. 